\section{Using Mount Fuji for diagnosis of tension pneumocephalus}

\author{
Rohat Ak, Fatih Doğnay, \\ Özge Ecmel Onur \\ Department of Emergency Medicine, \\ Fatih Sultan Mehmet Education and \\ Research Hospital, Istanbul, Turkey
}

A 71-year-old-woman was admitted to our emergency department because of headache, vomiting and nausea. She had undergone endoscopic sinus surgery the week before. 0 n examination, her Glasgow scale was 15/15 and her vital signs were stable. An axial non-contrast head computed tomography (CT) demonstrated a massive accumulation of air that was compressing the frontal lobes which was called Mount Fuji sign (Figure 1). She was operated immediately and a control CT scan demonstrated normal cerebral parenchyma (Figure 2). She was discharged from the hospital on the fifth day without any neurological sequelae. Mount Fuji sign refers to the presence of air between the tips of frontal lobes giving the appearance of Mount Fuji and this sign is indicative of a tension pneumocephalus. The Mount Fuji sign on CT scan is useful in discriminating a tension from a non-tension pneumocephalus. Tension pneumocephalus occurs when the intracranial air causes a mass effect and the brain is compressed. It has been reported to occur in a variety of situations, including posterior fossa surgery in the sitting position, use of an indwelling cerebrospinal drainage device, trauma, otogenic infections, chronic subdural hematoma drainage, ${ }^{1}$ and even spon-

\section{taneously. ${ }^{2}$}

Generally, the most common symptoms of tension pneumocephalus are altered consciousness, headache, generalized convulsions, or restlessness, ${ }^{3}$ but even cardiac arrest caused by tension pneumocephalus. ${ }^{4}$

The discrimination of tension and non-tension pneumocephalus is crucial to prevent serious conditions.

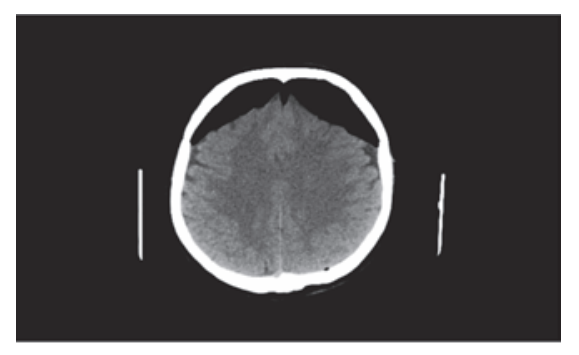

Figure 1. Axial computed tomography scan demonstrating a massive accumulation of air compressing the frontal lobes (i.e., Mount Fuji sign).

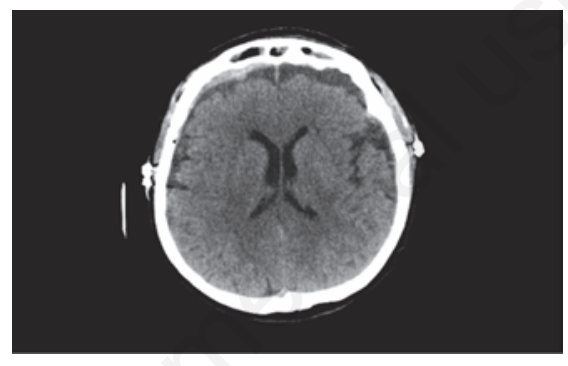

Figure 2. A control computed tomography scan demonstrating normal cerebral parenchyma.
Correspondence: Rohat Ak, Department of Emergency Medicine, Fatih Sultan Mehmet Education and Research Hospital, 34752 Istanbul, Turkey.

Tel: +90.216 .5783000 - Fax: +90.216 .5750406$

E-mail: rohatakmd@gmail.com

Key words: Tension pneumocephalus; Mount Fuji sign; Emergency medicine.

Received for publication: 10 January 2016. Accepted for publication: 18 January 2016.

This work is licensed under a Creative Commons Attribution 4.0 License (by-nc 4.0).

CC Copyright R. Ak et al., 2016

Licensee PAGEPress, Italy

Emergency Care Journal 2016; 12:5726

doi:10.4081/ecj.2016.5726

\section{References}

1. Paemeleire K, Santens P, Boon P. Mount Fuji sign following otogenic meningitis. Acta Neurol Belg 2008;108:116.

2. Heckmann JG, Ganslandt 0. The Mount Fuji sign. New Engl J Med 2004;350:1881.

3. Satapathy GC, Dash HH. Tension pneumocephalus after neurosurgery in the supine position. Brit J Anaesth 2000;84:115-7.

4. Thiagarajah S, Frost EA, Singh T, Shulman K. Cardiac arrest associated with tension pneumocephalus. Anesthesiology 1982;56: 73-5. 